\title{
Potential Solutions in Radiation Hormesis
}

\author{
Masao Takatori ${ }^{1, *}$, Makoto Yagi $^{2}$ and Sadao Hattori ${ }^{3}$ \\ ${ }^{1}$ Takatori Clinic of Internal Medicine, Kawasaki, Japan \\ ${ }^{2}$ Lead and Company Co., Ltd., Yokohama, Japan \\ ${ }^{3}$ Central Research Institute of Electric Power Industry, Aichi, Japan
}

\begin{abstract}
This study summarizes up-to-date information about the biopositive effects of low radiation treatment (LRT), radiation hormesis, and our experimental devices. In addition, we present a favorable treatment result in a patient with advanced rectal carcinoma who received LRT at home using a radon gas aspirator. The patient was a 61-year-old man who underwent proctectomy in 2010. During the additional first-line chemotherapy, apparent increases in tumor makers identified multiple remote metastases in the lung, sacrum and liver. Sacrum pain limited his activity of daily living and impeded his coming to our facility for LRT. Then, we decided to provide him home LRT using a radon gas aspirator. He inhaled radon gas for 15 minutes at least 3 times a day at home, resulting in remarkably reduced tumor markers and sacrum pain relief. He could walk, keep sitting up without support and sleep in the spine position again after receiving home LRT. No influence of radon gas inhalation on the second-line chemotherapy was observed. The favorable effects of LRT lead us to believe that the newly-developed devices will provide the clinical significance on malignant diseases. To establish the LRT regimen, further clinical investigation and data accumulation are thus called for.
\end{abstract}

Keywords: Alternative treatment, low radiation treatment, radon gas, malignant diseases.

\section{INTRODUCTION}

Low radiation treatment (LRT), radiation hormesis, is first reported by Dr. Luckey $[1,2]$ with the compiled data on thousands of people whose workplace exposed to low-dose radiation. Other investigators also accumulated data to clarify the effects of exposure to low-dose radiation [3-5]. It is well known some facilities providing radiation hormesis in Japan and Europe (e.g. Gesteiner Heilstollen in Bad Gastein, Austria) where people can inhale radon gas emanated from radon springs and receive low-dose radiation directly from radioactive mineral at the same time. Low dose radiation elevates immune response, and it may reduce rather than increase the risk of cancer [6]. Radiationrelated health effects have long been a focus of attention; particularly, its influence and radiation-related diseases have become major concerns after radiation leaks at the Fukushima nuclear power plant triggered by the Great East Japan Earthquake on March 11, 2011. Here, we present a case report treated with LRT using a newly-developed experimental device at home and up-to-date information about the biopositive effects of LRT

\section{A CASE REPORT}

The patient was a 61-year-old man diagnosed with advanced rectal carcinoma. The clinical course is shown in Figure 1. He started to receive chemotherapy

*Address correspondence to this author at 13-6, Yagami, Saiwai-ku, Kawasaki, Kanagawa, 212-0056, Japan; Tel: +81-44-580-3132; Fax: +81-44-588-0118; E-mail: mcyy@mtc.biglobe.ne.jp after proctectomy in 2010. During the additional firstline chemotherapy, apparent increases in tumor makers (carcinoembryonic antigen: CEA and CA19-9) were observed; multiple remote metastases were identified in the lung, sacrum and liver. Sacrum pain gradually got worse, which limited his activity of daily living, only lying in bed in the lateral spine position. We evaluated the cancer resistance to the first-line chemotherapy and decided to use radon gas before the second-line chemotherapy was initiated. The nature and purpose of LRT and risks involved were fully explained to the patient, who then provided written informed consent to receive LRT. Since scrum pain impeded his coming to our facility for receiving LRT, he received radon gas inhalation for 15 minutes at least 3 times a day using a radon gas aspirator (Figure 2) at home. No significant changes in tumor size or its location were observed after home LRT; however, tumor makers were remarkably reduced. Of note, the patient relieved from sacrum pain, which dramatically improved his activity of daily living and made him able to walk, keep sitting up without support and sleep in the spine position again. No influence of radon gas inhalation on the second-line chemotherapy was observed.

\section{DISCUSSION}

In the present case, we provided the newlydeveloped experimental device for home LRT because the deteriorating conditions prevented the patient to come to our facility. This device uses ultrasonic to clarify the clinical significance of inhaling radon gas 


\section{Clinical course}

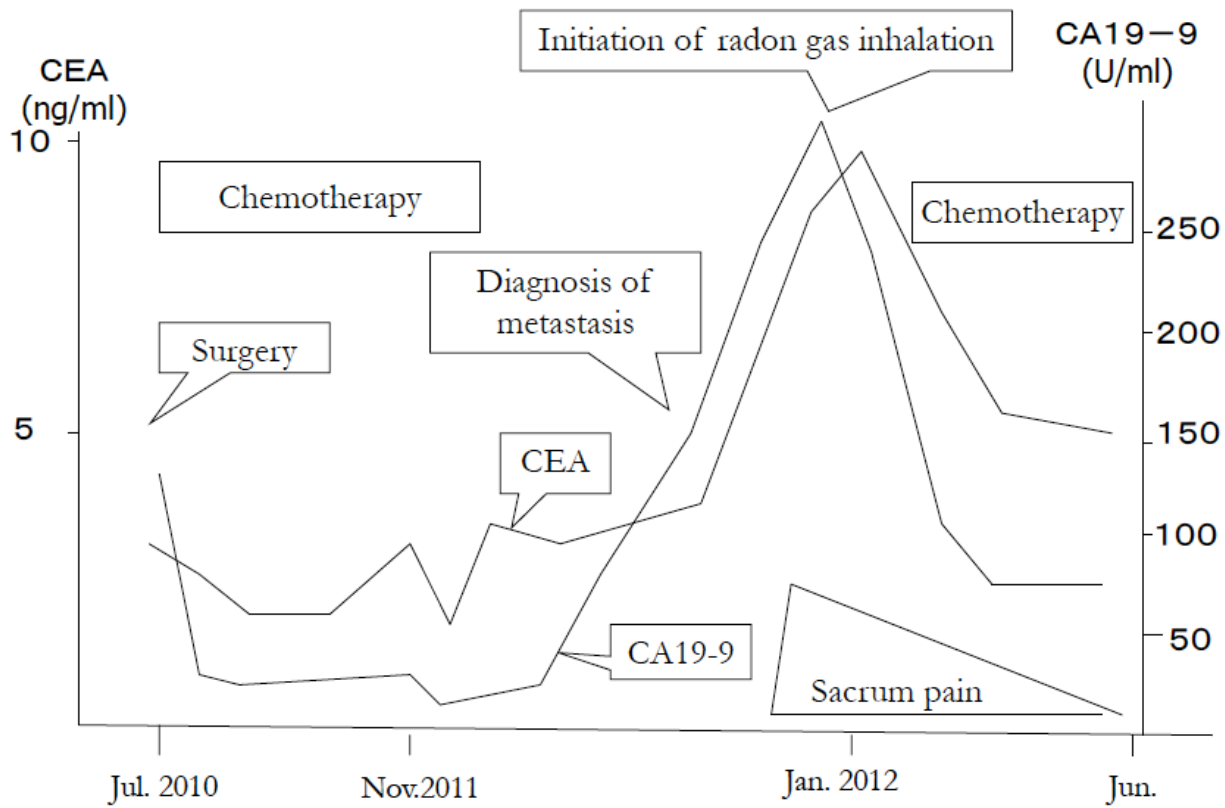

Figure 1: Clinical course of a patient who revealed multiple remote metastases after proctectomy and first-line chemotherapy.

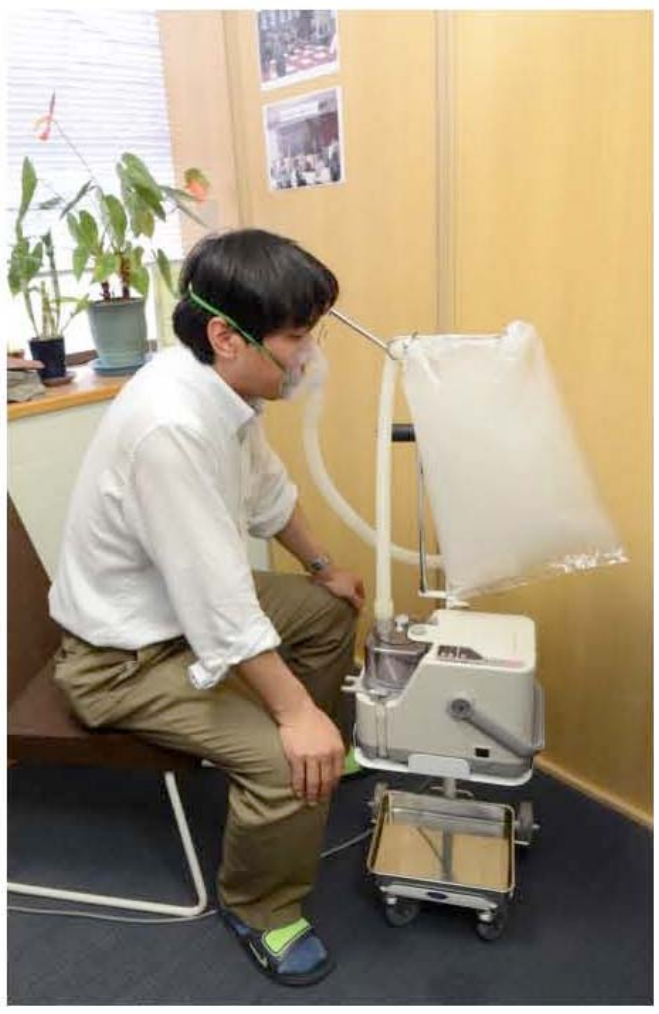

Figure 2: Radon gas aspirator.

Radon gas is gathered in bag; a patient inhales it using a face mask.

with $\alpha$ ray and provides the stable level of radon mist (over $17,000 \mathrm{Br} / \mathrm{m}^{3}, \mathrm{Rn}-222$ ) at a breath calculated with ALPHA-Scint (TRACERLAB Co., Germany). High bioactivity of a ray is expected by inhaling radon gas. Generally, a patient inhales radon gas using a mask provided from the vinyl bag attached to the closed circuit in the isolated room. Therefore, no one except the patient inhales the high level of Rn-222. Because of its specific gravity, residual $\mathrm{Rn}-222$ in the expiratory gas is usually subsided and diffused immediately on the floor with reduced personal exposure risks. The treatment regimen has not been fully established yet; however, our preliminary data showed improvement in different diseases and conditions, such as alleviation of chemotherapy-related appetite loss, disappearance of lung metastasis after esophageal cancer surgery and no specific side effects. In this case, home LRT using radon gas was initiated before the induction of secondline chemotherapy. Therefore, there were two possibilities for evaluating the significance of gas inhalation during the clinical course. One was that the clinical significance of gas inhalation was independent to the effect of chemotherapy. The other was the synergism of gas inhalation and chemotherapy. The difference in the regimen of chemotherapy is the use of oxaliplatin or CPT-11. In our patient, the synergism between gas inhalation and CPT-11 should be considered as an influential factor for the clinical course.

Nowadays, an experimental radioactive sheet (INSPECTOR, SE Co. USA) has also been developed 
for the clinical use of continuous $X$-ray radiation exposure (Figure 3 ) which might be another choice for home LRT. This sheet is made from silicone, $30 \times 30 \mathrm{~cm}$ in size. The radioactive levels of the sheet can be changed in each occasion, in the range approximately $40 \mu \mathrm{SV} / \mathrm{hr}$ to $2 \mathrm{mSV} / \mathrm{hr}$. This radioactive sheet consists of beta ray and predominant gamma ray. The sheet, originally developed as wallpaper, can be attached directly to the front and back side of the body, leading to easy use for home treatment. Since direct attachment to the skin causes an itch; more research is thus necessary to improve the quality of the sheet. The experimental use of this sheet resulted in tumor growth retardation in a female patient with advanced gastric cancer and in a male patient with pancreatic cancer.

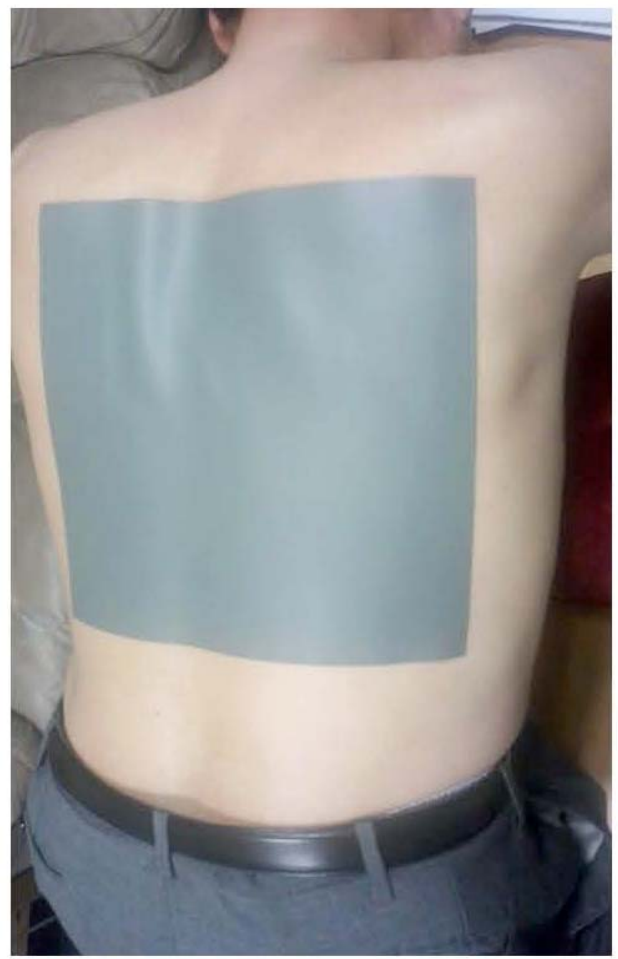

Figure 3: Radioactive sheet attached to the patient's back.

The other sheet was also attached to the front of the body. When a patient moves, flexible adjustment is necessary not to be loosen.

Our previous study reported the clinical significance of LRT in the experimental therapy room in our facility which can supply both direct radiation from the wall and indirect radiation from inhaling radon gas (Lead \& Comp; [7]). Radon gas emanates from the watersprinkled wall made from rich monazite mixture which was excavated from private mountains in Japan. Patients can receive low-dose radiation directly from radioactive mineral. Patients presenting to our facility have various backgrounds, although, the biopositive effects of LRT are identified in each study patient, including anti-cancer effects, alleviated general conditions and reduced chemotherapy-related side effects. It has not been unsolved the exact level of radiation one can receive and the establishment of treatment regimen using radiation at the appropriate dose; the results obtained so far are controversial. The most ideal level of LRT is estimated one hundred times higher than the average natural radiation exposure received from natural sources [1, 2]. Several studies have reported that human gene still has restoration ability even at the higher radiation level [8-11]. A recent study by Dr. Doss [6] has insisted that liner nonthreshold model, which pays exclusive attention to DNA damage, completely ignores immune system response in its estimation of cancer risk. The current radiation safety paradigm and regulations and the consequent fear of low dose radiation have prevented progress in dealing with these unsolved problems in human health. Accordingly, the investigation of LRT at the increased dose in human being and its efficacy should be carried out as a next exploration.

Recently, we have renovated the LRT room in our facility which keeps the average radiation level of 2 $\mathrm{mSV} / \mathrm{hr}$ anywhere inside the room even at a distance of $10 \mathrm{~cm}$ from the wall (INSPECTOR, SE Co. USA) and the radon concentration at $100,000 \mathrm{~Bq} / \mathrm{m}^{3}$ (DOSEMAN, SARD Co. Germany). Compared to the previous room, patients can receive higher radiation in the new room. There has been only a handful of data supporting the routine use of renewed system, further data accumulation is thus indispensable.

The favorable effects of LRT lead us to believe that the newly-developed devices will provide the clinical significance on malignant diseases. These facts are important for the entire field of cancer therapy. To establish the LRT regimen, further clinical investigation and data accumulation are thus called for.

\section{REFERENCES}

[1] Lucky TD. Physiological benefits from low levels of ionizing radiation. Health Phys 1982; 43: 771-89. http://dx.doi.org/10.1097/00004032-198212000-00001

[2] Lucky TD. Radiation hormesis. CRC Press. Boca Raton, Florida 1999; p. 239.

[3] Yamamoto $\mathrm{O}$, Seyama $\mathrm{T}$, Ito $\mathrm{N}$, Fujimoto $\mathrm{N}$. Oral administration of tritiated water (HTO) in mouse. III: Low dose-rate irradiation and threshold dose-rate for radiation risk. Int J Radiat Biol 1998; 73: 535-41. http://dx.doi.org/10.1080/095530098142086

[4] Kondo S. Health effects of low-level radiation. Kinki University Press, Osaka. Japan Medical Physics Publishing, Madison, Wisconsin 1993. 
[5] Yamaoka K, Edamatsu R, Mori A. Increased SOD activities and decreased lipid peroxide levels in rat organs induced by low-dose x-irradiation. Free Radic Biol Med 1991; 11: 299306.

http://dx.doi.org/10.1016/0891-5849(91)90127-O

[6] Doss M. Shifting the paradigm in radiation safety. Dose Response 2012; 10: 562-83.

http://dx.doi.org/10.2203/dose-response.11-056.Doss

[7] Takatori M, Hattori S, Yagi M. Clinical significance of lowdose radiation therapy: radiation hormesis. Int $\mathrm{J}$ Low Radiation 2010; 7: 511-19. http://dx.doi.org/10.1504//JLR.2010.037672

[8] Tubiana M, Aurengo A, Averbeck A, Masse R. Recent reports on the effect of low dose of ionizing radiation and its dose-effect relationship. Radiat Environ Biophys 2006; 44: 245-51.

http://dx.doi.org/10.1007/s00411-006-0032-9
[9] Tubiana M, Aurengo A, Averbeck A, Masse R. The debate on the use of linear no threshold for assessing the effects of low doses. J Radiol Prot 2006; 26: 317-24. http://dx.doi.org/10.1088/0952-4746/26/3/N01

[10] Vilenchik MM, Knudson AG. Radiation dose-rate effects, endogenous DNA damage, and signaling resonance. Proc Natl Acad Sci USA 2006; 103: 17874-79. http://dx.doi.org/10.1073/pnas.0607995103

[11] Feinendegen LE, Pollycove M, Neumann RD. Whole-body responses to low-level radiation exposure: new concepts in mammalian radiobiology. Exp Hematol 2007; 35: 37-46. http://dx.doi.org/10.1016/j.exphem.2007.01.011

Received on 07-03-2013

DOI: http://dx.doi.org/10.6000/1929-2279.2013.02.02.2

(C) 2013 Takatori et al.; Licensee Lifescience Global.

This is an open access article licensed under the terms of the Creative Commons Attribution Non-Commercial License (http://creativecommons.org/licenses/by-nc/3.0/) which permits unrestricted, non-commercial use, distribution and reproduction in any medium, provided the work is properly cited. 